SOUTHERN BRAZILIAN, JOURNAL OF CHEMISTRY

SOUTH. BRAZ. J. CHEM., Vol. 19,No.19, 2011

\title{
TADASHI TOKUHIRO, PROMINENT SPECIALIST IN NMR \\ RELAXATION PHENOMENA AND MOLECULAR DYNAMICS
}

Lavinel G. Ionescu

Scienco Scientific Consulting Services

Viamão, Rio Grande do Sul, BRASIL

and

Sarmisegetusa Research Group

Santa Fe, New Mexico, USA

\begin{abstract}
Tadashi Tokuhiro was born in Yokohama, Japan in 1930 and passed away in Grapevine, Texas, USA in 2010. He obtained a Ph.D. in Chemical Physics from Tokyo Institute of Technology in 1962. He held faculty positions at many universities, including the University of Detroit, Massachusetts Institute of Technology and Missouri University of Science and Technology. His main research interest dealt with physical and engineering application of gels, nuclear magnetic resonance relaxation phenomena, molecular dynamics and characterization of biotissues by NMR methods. He published many scientific articles in widely respected journals from Japan, United States and Great Britain.
\end{abstract}

KEY WORDS: History of Chemistry, Physical Chemistry, Chemical Physics, NMR Spin Lattice Relaxation, Molecular Dynamics

\section{RESUMO}

Tadashi Tokuhiro nasceu in Yokohama, Japão em 1930 e faleceu em Grapevine, Texas, USA. Ele obteve o título de Ph D. em Química Física do Insituto de Tecnologia de Tóquio em 1962. Ocupou cargos de professor em várias universidades, incluindo University of Detroit, Massachusetts Institute of Technology e Missouri University of Science and Technology. As suas atividades de pesquisa trataram de propriedades fisicas e aplicações de géis, fenômenos de relaxamento de ressonância magnética nuclear, dinâmica molecular e caracterizaçâo de tecidos biológicos com métodos de RMN. Ele publicou muitos artigos cientificos em revistas de alto nivel do Japão, Estados Unidos e Grã Bretanha.

PALAVRAS CHAVE: Histónia da Química, Fisico-Química, Física Química, Relaxamento Espin-Rede de RMN, Dinâmica Molecular 


\title{
SOUTHERN BRAZILIAN, JOURNAL OF CHEMISTRY \\ SOUTH. BRAZ. J. CHEM., Vol. 19, No.19, 2011
}

\author{
Tadashi Tokuhiro, Prominent Specialist in Chemical Physics
}

Tadashi Tokuhiro was born in Yokohama, Japan on February 26, 1930 and passed away in Grapevine, Texas on August 10, 2010.

His father was a structural/architectural engineer for Japan's Sun (Shell) Oil Company with "Western" habits. Together with his sisters he spent the early years in Yokohama .

In 1956 he married Reiko, his wife for forty nine years. They had two children, a girl, named Asako and a boy, Akira.

He received the Bachelor of Science Degree in Chemistry from Tokyo University of Science in 1957. He obtained the Master of Science Degree in Physical Chemistry from the Tokyo Imperial Institute of Science and Technology (now, Tokyo Institute of Technology) in 1959 and was awarded the Doctor of Philosophy Degree in Chemical Physics from the same institution in 1962.

From 1962 to 1965, Tadashi Tokuhiro held the position of Research Associate at the Research Laboratory of Spectroscopy of the Tokyo Institute of Technology.

Early in his scientific career, in 1964, he was the recipient of the Matsunaga Science Foundation Award for Encouragement of Young Scientists for his work on nuclear quadrupole resonance in solid organic substances.

During that time, many promising young scientists from throughout the world were attracted to the United States, very much alike to what happened during the golden age of the Roman Empire, when the world's best scientists and engineers went to Rome.

Tadashi Tokuhiro went to the United States in 1965 with the recommendation and kindness of key individuals like Colonel ImObersteg (Pentagon) and Reverend R.C. Halverson of Washington, DC. He began postdoctoral work with Professor Gideon Fraenkel at The Ohio State University in 1965 and continued as 
SOUTH. BRAZ. J. CHEM., Vol.19, No. 19, 2011

L.G. Ionescu

Research Associate until 1969 when he accepted a faculty position as Assistant Professor in the Chemistry Department of the University of Detroit. In 1974 he was promoted to Associate Professor. He worked at the University of Detroit for 15 years and played a very important role in the establishment of the Ph. D.

Program in Chemistry.

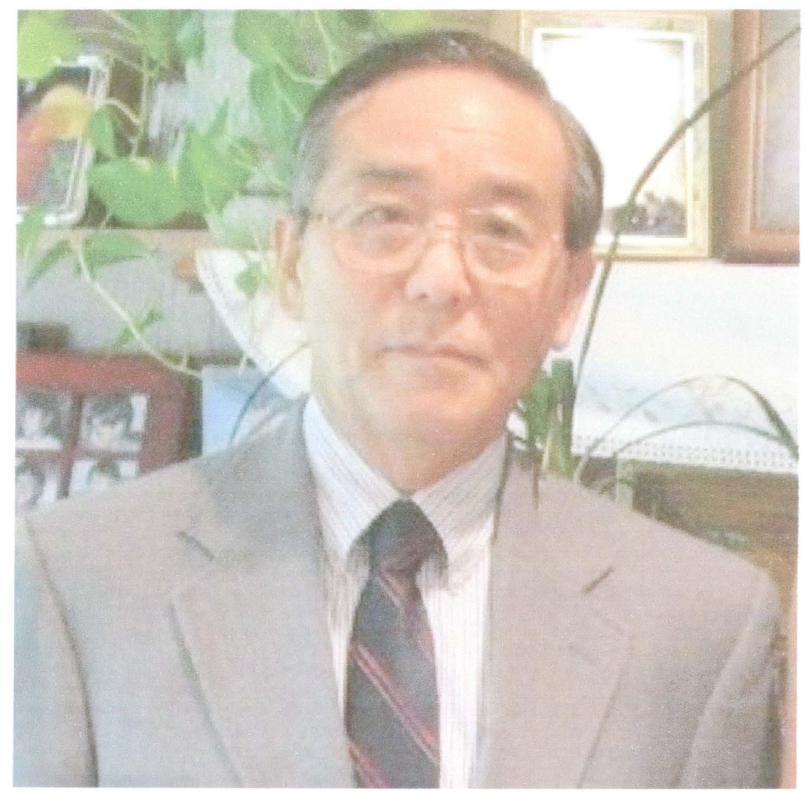

PROF. DR TADASHI TOKUHIRO (1930-2010)

Prof. Dr. Tadashi Tokuhiro held faculty positions at other universities including Loyola University (Chicago), New Jersey School of Medicine and Dentistry, Massachusetts Institute of Technology and the University of Missouri, Rolla (now, Missouri University of Science and Technology).

He was also staff scientist at the following institutions: Argonne National 
SOUTH. BRAZ. J. CHEM., Vol.19, No. 19, 2011

Tadashi Tokuhiro, Prominent Specialist in Chemical Physics

Laboratory (Solid State Science), MIT's Francis Bitter Magnet National

Magnet Laboraory, Bruker BioSpin, Brucker Analytische Messtechnik, GMBH,

Karlsruhe, Germany and Picker International (NMR/MRI).

At the Missouri University of Science and Technology he worked from 2002

to 2010, a few months before his death. He held the position of Adjunct Professor in the Graduate School and the Department of Chemistry.

His research interests dealt with physical science and engineering application of gels, nuclear magnetic resonance (NMR) relaxation phenomena, molecular dynamics and characterization of biotissues by NMR methods.

During the last ten years that he spent at the Missouri University of Science and Technology, he studied hydrogel/polymer gels using NMR and reported that the characteristic time scales of phenomena at the nano-scale were different from those in bulk aqueous phenomena.

Together with his son Akira Tokuhiro and Massimo Bertino, he was awarded various grants by the Department of Energy for nuclear energy engineering research (DOE NEER). They involved studies of metal binding capability of functional thermosensitive polymer networks and application of hydrogels to low level radioactive waste processing, enhancing reactor facility utilization at the University of Missouri-Rolla reactor.

VISIT OUR SITE: http://www.sbjchem.he.com.br 


\section{SOUTH. BRAZ.J. CHEM., Vol.19, No.19, 2011}

\section{G. Ionescu}

Prof. Dr. Tadashi Tokuhiro was our colleague during our tenure as a faculty member in the Department of Chemistry of the University of Detroit, Detroit, Michigan from 1975 to 1978.

We shared the responsibility of teaching undergraduate lecture and laboratory courses to chemistry and chemical engineering students.

Eventually, we became good friends and collaborated in various research projects, the most important one being the study of the process of micellization in aqueous solutions. Our study of the ternary system cetyltrimethylammonium bromidedimethyl sulfoxide-water $\left(\mathrm{CTAB}-\mathrm{DMSO}-\mathrm{H}_{2} \mathrm{O}\right)$, mainly by nuclear magnetic resonance spin-lattice relaxation and tensiometric techniques, eventually led to an unique model for a micelle. The preliminary results were presented at the $174^{\text {th }}$ National Meeting of the American Chemical Society in Chicago in 1977 and at the $52^{\text {nd }}$ Colloid and Surface Science Symposium, sponsored by the Oak Ridge National Laboratory, in Knoxville, Tennessee in 1978. A copy of the abstracts of the papers is given on the following pages.

The first diagram of the unique model was published in 1984 in Surfactants in Solution, K.L. Mittal and B. Lindman, Eds., Vol. 2, Plenum Press, New York, 1984. (Cf. L. G. Ionescu, F. Nome and L.S. Romanesco, pp.789-801).

Prof. Dr. Tadashi Tokuhiro was the best example that we have witnessed in terms of the preparation of experimental samples for precise measurements. He had an extraordinary patience, took a lot of care and seemed to feel a pleasure doing experiments. Like very few scientists, he managed to do research and experimental work up to the age of 80 years, a few months before his passing away. 
SOUTHERN BRAZILIAN, JOURNAL OF CHEMISTRY

SOUTH. BRAZ. J. CHEM., Vol. 19,No.19, 2011

\section{PHYS 39}

ABSTREATS OR RAPBS

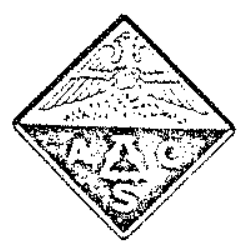

174th ACS Meeting

\section{American Chemical Society \\ Port City Press, Ine. \\ Baltimore, Md.}




\title{
SOUTHERN BRAZILIAN, JOURNAL OF CHEMISTRY \\ SOUTH. BRAZ. J. CHEM. , Vol. 19,No.19, 2011
}

\author{
L. G. Ionescu
}

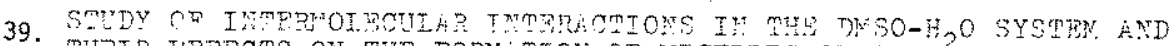

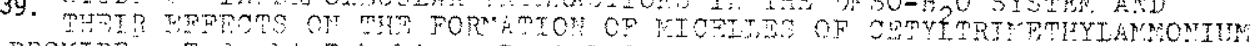

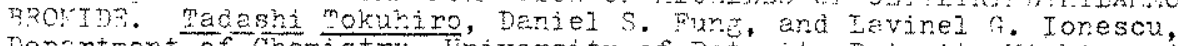
Demartment of chemistry, Thiversity of Detroit, Detroit, Wichigan 48221.

Surface tension measurerents of water-timethylsilfoxide (DNso) solutions of cetyltrimethylamonium bromide (Cma) indicate that the Iiruid stmuctures of the solvent systems play ar important role in the

PHYS

formation of micelles. The addition of DMSO to water causes a significant increase in the critical micellar concentration (CNC) of CTAB. At a DMSO mole fraction (X) of 0.366 , micelle formation was not observed. Proton spin-lattice relaxaison rate $\left(1 / \mathrm{m}_{1}\right)$ for the methylene groups, the methyl groups attached nitrogen and the end methyl eroup of CTAB were setermined in $\mathrm{D}_{2} \mathrm{C}$ and $\mathrm{D}_{2} \mathrm{O}-\mathrm{DNSO}-\mathrm{d} 6^{\mathrm{m}}$ mixtures at $28^{\circ} \mathrm{C}$. As compared to the $\left(1 / \mathrm{T}_{1}\right)(\mathrm{Cu})$ values $\left(0.017 / \mathrm{s}\right.$ in $\left.\mathrm{D}_{2} 0\right),\left(1 / \mathrm{T}_{1}\right)$ for both methyl protons were very large $(\sim 2 / s)$. The $\left(1 / \mathrm{F}_{1}\right)(\mathrm{CH})$ values in both $\mathrm{D}, \mathrm{O}$ and D,O-DMSO-d mixtures above CMC were sllghtlf ereater than those below CFC. An increase in $\left(1 / \mathrm{T}_{1}\right)\left(\mathrm{CH}_{2}\right)$ was caused by the addition of DMSO-d 6 to $D_{2} 0$, i.e., $0.03 / \mathrm{s}(X=0.098)^{2}$ and $0.074 / \mathrm{s}(X=0.366)$. These results reveal that an increase in structuring of the solvent system apparently ghifts the COC to higher concentrations. Preliminary results obtained for CTAB in $N$, N-dimethyl formanide-water solutions indicate a similar kind of intermolecular interactions.

40. CONDUCTANCE BEHAVIOR OF LONG-CHAIN AMINE HXDROCHLORIDES IN 2-METHOXYETHANOL.

Barbara J. Barker and Thomas Mullin, Department of Chemistry, Hope College, Holland, MI 49423 and Joseph Rosenfarb, Department of Chemistry, University of Florida, Gainesville, FL 32611 .

The behavior of a series of colloidal electrolytes in 2-methoxyethanol (methyl cellosolve), a mediun of relatively low specific conductance $\left(4-6 \times 10^{-8} \mathrm{ohm}^{-1} \mathrm{~cm}^{-1}\right)$ and dielectric constant (16.8) and moderate viscosity $(1.54 \mathrm{cP})$, was investigated by conductance techniques at $25^{\circ} \mathrm{C}$. Included in the study were octyl-, decyl-, dodecyl-, tetradecyl-, hexadecy1-, and octadecylamine hydrochlorides. All conductance data were evaluated by the Fuoss-Shedlovsky, Fuoss-Onsager, and Fernández-Prini expanded form of the Pitts and Fuoss-Hsia equations. As expected, the limiting equivalent conductances of the electrolytes decrease as the crystallographic radii of the cations of these salts increase. Little difference is observed in the extent of association of the six longchain quaternary anmonium salts in 2-methoxyethano1; these salts appear to behave as simple $1: 1$ electrolytes within the concentration range of $1-28 \times 10^{-4} \mathrm{M}$. Included in the present discussion are a sumnary of the previously investigated conductance behavior of these long "chain salts in water and a general review of colloidal electrolyte behavior in solution.

VISIT OUR SITE: http:/www.sbjchem.he.com.br 
SOUTHERN BRAZILIAN, JOURNAL OF CHEMISTRY

SOUTH. BRAZ. J. CHEM. , Vol. 19,No.19, 2011

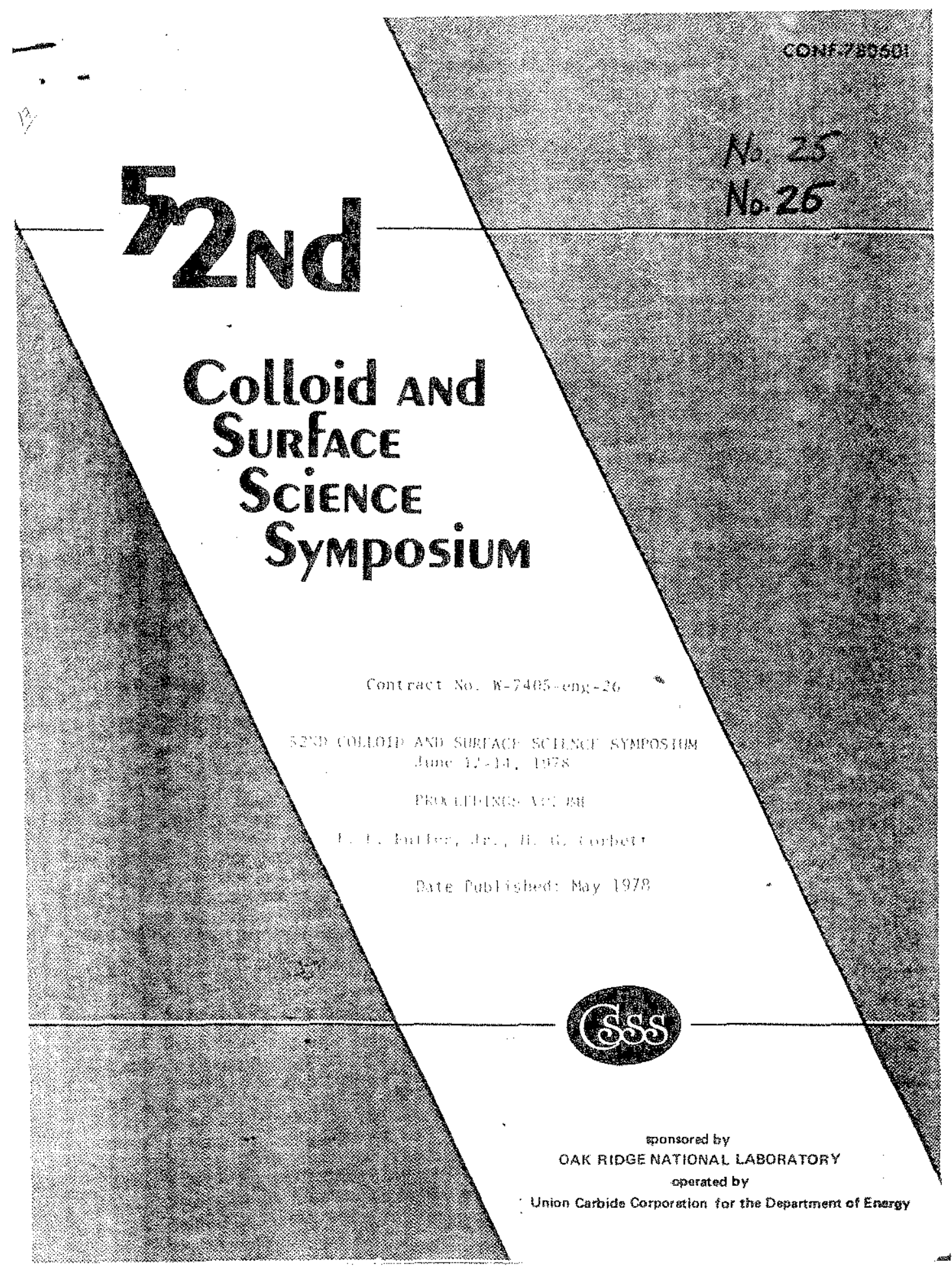




\title{
SOUTHERN BRAZILIAN, JOURNAL OF CHEMISTRY SOUTH. BRAZ. J. CHEM. , Vol. 19,No.19, 2011
}

\section{G. Ionescu}

\author{
162 \\ sand colzoid and surface seience symposium \\ June $22-24,2978$ \\ University of Tennessee, Knoxvizie, Tenn. 37296
}

EFFECT OF POLAR SOLVENTS ON THE FORMATION OF MICELLES OF

CETYLTRTMETHYLAMMONIUM BROMIDE IN AQUEOUS SOLUTIONS. LavineI G. IONESCU, Tadashi Tokuhiro and Benjamin J. Czerniawski, Department of Chemistry, University of Detroit, Detroit, Michigan 48221 .

\section{Long Abstract}

Many properties of solutions of the surfactant cetyltrimethylammonium bromide (CTAB) in water have been studied in great detail. Of particular interest is the critical micellar concentration, CMC, which is the minimum concentration of surfactant at which micelles are formed. We have determined the critical micellar concentrations of aqueous solutions of CTAB containing various amounts of dimethylsulfoxide (DMSO), N, N-dimethyl formamide (DMF) and $\mathrm{N}, \mathrm{N}$-dimethylacetamide (DMA) at $25^{\circ}$ and $40^{\circ} \mathrm{C}$ by means of surface tensiometry. The experimental measurements were carried out with a Fisher Model 21 Surface Tensiomat. In general, the experimental results indicate that micelle formation is hindered by increasing the temperature. A11 three cosolvents, DMSO, DMF and DMA have an inhibitory effect on the formation of micelles of CTAB. This effect is relatively small at low cosolvent concentrations, but it increases dramatically as the mole fractions of DMSO, DMF and DMA approach 0.33 . This mole fraction corresponds to the formation of the stoichiometric hydrates DMSO $2 \mathrm{H}_{2} \mathrm{O}$ and DMF $2 \mathrm{H}_{2} \mathrm{O}$. At cosolvent mole fractions higher than 0.33 the formation of CTAB micelles does not appear to take place. The inhibitory effect on micelle formation is most pronounced for mixtures of water and $N, N$-dimethylacetamide. The $\Delta G^{\circ}$ values determined for the process of micelitization in the mixed solvent systems are comparable to those determined for the formation of micelles in water. The values obtained for $\Delta S^{\circ}$ micellization indicate than an increase in the ordering of the surfactant-water-cosolvent system takes place as the mole fraction of cosolvent is in creased. This is consistent with a strong interaction, such as hydrogen bonding, between water and cosolvent. The inhibitory effect on micelie formation can be explained in terms of a decrease of hydrophobic forces in the ternary system due to interactions between water and cosolvent.

VISIT OUR SITE: http://www.sbjchem.he.com.br 


\title{
SOUTHERN BRAZILIAN, JOURNAL OF CHEMISTRY SOUTH. BRAZ. J. CHEM. , Vol. 19,No.19, 2011
}

\author{
163 \\ 52nd Cozzoid and Surface Science Symposium \\ June $22-74,2978$ \\ University of Tennessee, Knoxvizle, Tenn, 37296
}

PROTON SPIN-LATTICE RELAXATION MEASUREMENT IN AQUEOUS MICELLAR SYSTEMS CONTAINING DIMETHYLSULFOXIDE. Tadashi Tokuhiro, Lavine1 G. Ionescu and Daniel B. Fung, Department of Chemistry, University of Detroit, Detroit, Michigan, 48221.

\section{Long Abstract}

Although it is well recognized that the whole micellar structure is a bulk phase well distinct from the aqueous phase, information concerning molecular dynamics of surfactant monomers and molecules present in micelles is almost unavailable. In this work effect of intermolecular interactions on the formation of micelles and molecular motions of surfactant molecules were investigated by measuring proton spin-lattice relaxation rates for the methyl, N-methyl, and methylene groups of cetyltrimethylammonium bromide (CTAB) in water and water-DMSO mixtures at concentrations below and above the critical micellar concentration ( $\mathrm{CMC}$ ).

\section{(2) Be low $C M C$}

The experimentally measurable relaxation rates for the above three proton groups (R) of $C T A B\left[\left(1 / T_{1}\right) R(W\right.$ or $\left.B)\right]$ consist of several contributions where $W$ and $B$ denote water and water-DMSO mixture. The values of these contributions are listed in Table I.

\section{(2) Above CMC} sed as

The experimentally measurable relaxation rates can be expres-

$$
\left.\left(1 / T_{1}\right)_{R(W}^{\exp t} \text { or } B\right)=\left(1 / T_{1}\right)_{R(W \text { or } B)}^{M}(1-C M C / C)+\left(1 / T_{1}\right)_{R(W \text { or } B)}^{S}(C M C / C)
$$

where $C$ is the total concentration of CTAB and $M$ stands for micelles. There are several contributions to the first term in Eq. (1). The values of these are also listed in Table I.

Our previous study revealed that the addition of DMSO to water increased "structuring" in the liquid system" and this was attributed to a strong contribution from DMSO molecules which are directly involved in the structure of this binary liquid through hydrogen bonding with water protons. This increased "structuring" in the liquid system played an important role and disturbed the formation of micelles as manifested by the solventcomposition dependence of intra and intermolecular relaxation rates. (See the third and fourth column in Table I.) It is evident that the strength of intermolecular interactions between water and DMSO overcomes the "hydrophobic effect" which is the main driving force to form micelles in water.

From the values shown in Table I and various correlation times evaluated from $1 / T_{1}$ values the "rigidity" or "fluidity" of micelles in water can be described as follows: 1) the "fluidity" of the methylene groups in micelles is comparable to that of monomers dispersed in water or Iiquid hydrocarbons, 2) within micelles, the "rigidity" of the tail part of the CTAB molecule is greater than that of the head group, and 3) the "fluidity" of the methylene group is larger than that of either the tail or the head groups by factors of over a few hundred. 


\section{G. Ionesca}

The generalized picture that emerges for the CTAB micelles consists of three well-delineated regions: 1) the center that contains the terminal methyl groups and is fairly rigid, 2) a fluid area containing most of the methylene groups and, 3) a relatively rigid surface consisting essentially of the $N$-methyl head groups and the corresponding counter ions.

Table I. Intra and Intermolecular proton Spin-Lattice Relaxation Rates at $28.2^{\circ} \mathrm{C}$.

\begin{tabular}{|c|c|c|c|c|c|c|}
\hline & $X(D M S O)$ & $\begin{array}{l}\left(\frac{1}{\mathrm{~T}_{1}}\right)_{\mathrm{R}}^{\mathrm{S}}(\text { intra }) \\
\times 10^{2}\left(\mathrm{~S}^{-1}\right)\end{array}$ & $\left\{\begin{array}{l}\left(\frac{1}{\mathrm{~T}_{1}}\right) \begin{array}{l}\text { S (inter }) \\
\mathrm{R}-\mathrm{CTAB}\end{array} \\
\times 10^{2}\left(\mathrm{~S}^{-1}\right) *\end{array}\right.$ & 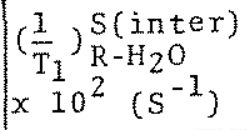 & $\left\{\begin{array}{l}\left(\frac{1}{\mathrm{~T}_{1}}\right)_{\mathrm{R}}^{\mathrm{M}} \\
\times 10^{2}\left(\mathrm{~S}^{-1}\right) * *\end{array}\right.$ & {$\left[\begin{array}{l}\left(\frac{1}{\mathrm{~T}_{1}}\right)_{\mathrm{R}-\mathrm{H}_{2} \mathrm{O}}^{\mathrm{M}(\text { inter }} \\
\times 10^{2}\left(\mathrm{~S}^{-1}\right)\end{array}\right.$} \\
\hline$\left(\mathrm{H}_{2}\right)_{15}$ & $\begin{array}{l}0 . \\
0.098 \\
0.366\end{array}$ & $\begin{array}{r}1.0 \\
2.5 \\
59.0\end{array}$ & $\begin{array}{l}0.80 \\
0.52 \\
0 .\end{array}$ & $\begin{array}{l}- \\
- \\
-\end{array}$ & $\begin{array}{l}1.80 \\
3.54 \\
-\end{array}$ & $\begin{array}{l}- \\
-\end{array}$ \\
\hline $\mathrm{CH}_{3}$ & $\begin{array}{l}0 . \\
0.098 \\
0.366\end{array}$ & $\begin{array}{l}102 \\
120 \\
188\end{array}$ & $\begin{array}{c}44.0 \\
20.0 \\
0 .\end{array}$ & $\begin{array}{r}1,260 \\
357 \\
\end{array}$ & $\begin{array}{r}236 \\
217 \\
-\end{array}$ & $\begin{array}{c}\sim 0 . \\
\sim 0 \\
\quad-\end{array}$ \\
\hline $\mathrm{N}^{+}\left(\mathrm{CH}_{3}\right)_{3}$ & $3\left[\begin{array}{l}0 . \\
0.098 \\
0.366\end{array}\right.$ & $\begin{array}{l}105 \\
151 \\
179\end{array}$ & $\begin{array}{c}43.0 \\
27.0 \\
0 .\end{array}$ & $\begin{array}{r}1,740 \\
199 \\
-\end{array}$ & $\begin{array}{r}275 \\
208 \\
-\end{array}$ & $\begin{array}{l}\sim 0 . \\
<620\end{array}$ \\
\hline
\end{tabular}

* $\mathrm{C}=3.2 \mathrm{mM}$

$* *\left(1 / T_{1}\right)_{R}^{M}=\left(1 / T_{1}\right)_{R}^{M}($ intra $)+\left(1 / T_{1}\right)_{R-C T A B}^{M}($ inter $)$ and at $C=13 \mathrm{mM}$.

1. T. Tokuhiro, L. Menafra and H. H. Szmant, J. Chem. Phys. 61, 2275 (1974). 


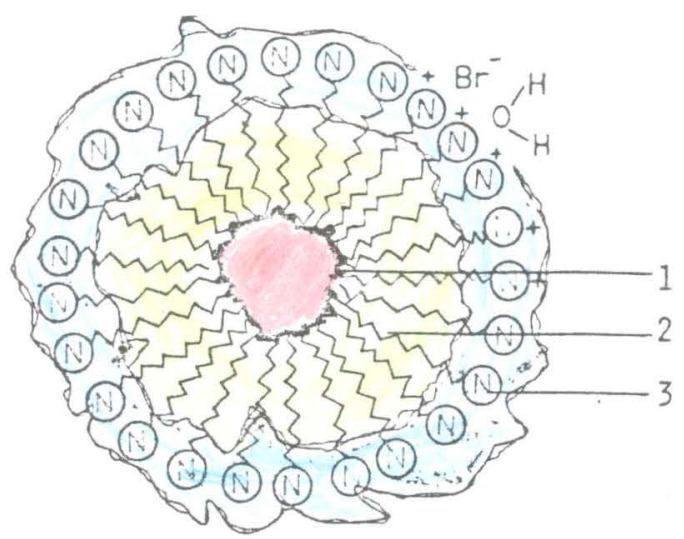

1 - Relatively Rigid CENTER CONTAining terminal METHYL GROUPS

2 - FiUID REgION CONTAINING MOST OF THE METHYLENE

3 - RELATIVELY RIGID SURFACE CONSISTING MAINLY OF THE N-METHYL GROUPS AND BROMIDE COUNTERIONS

Structure proposed for micelles of cetyltrimethylammonium bromide (CTAB) on the basis of NMR spin lattice relaxation time measurements. (Cf. Surfactants in Solution, Vol. 2, K.L.Mittal and B. Lindman, Eds, Plenum Press, New York, 1984).

VISIT OUR SITE: http://www.sbjchem.he.com.br 


\section{SOUTH. BRAZ. J. CHEM., Vol.19, No. 19, 2011}

\section{G. Ionescu}

At the University of Detroit, he had the reputation of a good, tough and strict Professor. As we mentioned above, we shared the responsibility of teaching physical chemistry to chemistry and chemical engineering undergraduate students. We used to rotate the responsibility of the disciplines. In this way the students had a "democratic" choice to choose the professor. It was just the question of waiting a semester.

We remember a chemical engineering student from Nigeris, Momoh, who took Physical Chemistry I with Professor Tokuhiro and failed. He was repeating the course with us. Momoh was almost late for the class that was early in the morning and at times he did not pay much attention.

On a certain date, we went to participate of a conference and our assistant gave an examination for us on the laws of thermodynamics. As usual, Momoh was late and when he got to the classroom he saw some strange people there. The room was used by a guest lecturer and the physical chemistry class was changed to a room in a nearby building. He did not see the note on the door, lost a lot of time finding the new place and failed the exam. He explained to us that he lost a lot of energy looking for the new classroom, his head got hot and could not think well. He became frightened at the idea of failing with us and having to repeat the course again with Professor T. Tokuhiro.

Since thermodynamics deals with the transformation of energy into heat and work, we gave Momoh a second chance and he eventually passed the course.

Prof. Dr. Tadashi Tokuhiro was active in community affairs and the propagation of science. He served as Vice-President and President of the Physical Sciences Section of the Michigan Academy of Sciences, Arts and Letters and participated in the "mokuyoki' choral groups, He enjoyed classical music, especially the Bach Cantata and travelled widely. 
SOUTH. BRAZ.J.CHEM., Vol.19, No. 19, 2011

14

Tadashi Tokuhiro, Prominent Specialist in Chemical Physics

Prof. Dr. Tadashi Tokuhiro lived some very difficult years as a youth during World War II, but was spared from major tragedies. His classes were often cancelled, he worked in a factory and saw B-29 bombers headed for Tokyo. The scenes he witnessed Tokyo in the part of the city hit by incendiary bombs left deep impressions that stayed with him for the rest of his life. He impressed people with his calm mood and his deep reflections.

Two of his doctoral students at the University of Detroit have contributed significantly to the development of chemistry in South America.

Dr. Luis Menafra, besides his effort in chemistry, was President (Rector) of the Universidad de la República, Montevideo, the most prestigious university in Uruguay.

Dr. Juanita Freer, faculty member at the Universidad de Concepción, made important contributions to the development of chemistry in Chile.

Prof. Dr. Tadashi Tokuhiro published a large number of articles dealing with chemistry, physical chemistry and chemical physics in widely respected journals in Japan, United States and Great Britain. A list of representative publications is given at the end of this article.

ACKNOWLEDGMENT. We thank Prof. Dr. Akira Tokuhiro of the University of Idaho for his help and assistance.

\section{SOME REPRESENTATIVE PUDLICATIONS}

1. T. Tokuhiro, A. T. Tokuhiro, "Characteristic role of cross-linker on thermally induced volumetric contraction-expansion processes in poly ( $N$-isopropylacrylamide) networks and water systems", J. App. Polymer Sci. 112, 3177-3184 (2009)

2. T. Tokuhiro, A. T. Tokuhiro, "Temperature dependence of density of polymer gels :Effects of ionizable groups in copoly ( $\mathrm{N}$-isopropylacrylamide/acrylic acid or sodium acrylate) - water systems", Polymer 49, 525-533 (2008) 


\section{SOUTH. BRAZ. J. CHEM., Vol.19, No. 19, 2011}

L. G. Ionescu

3. T. Tokuhiro, S. S. Akella, J. W. Carey, A. T. Tokuhiro, "Metal binding capability of functionalized thermo-sensitive polymer networks and application of hydrogels to low-level radioactive waste processing", Proceedings of $15^{\text {th }}$ Intn'l Conf. Nucl. Eng., Nagoya, Japan (April, 2007), Paper\#: 15-10163 (8 pages)

4. T. Tokuhiro, "Temperature dependence of density of polymer gels 2. Poly $[N$ - (1,3-dioxolan-2ylmethyl)- $N$-methyl-acrylamide]-water or -alcohol system", J. Phys. Chem. B, 105, 11955-11960 (2001)

5. T. Tokuhiro, "Temperature Dependence of Density of Polymer Gels 1. A pycnometry method applied to poly( $\mathrm{N}$-isopropylacrylamide) - water system", J. Phys. Chem. B, 103, 7097-7101 (1999)

6. T. Tokuhiro, A. Appleby, A. Leghrouz, R. Metcalf, R. Tokarz, "Proton spin- lattice relaxation of water molecules in ferrous-ferric/agarose gel system", J. Chem. Phys. 105, 3761-3769 (1996)

7. T. Tokuhiro, T. Amiya, A. Mamada, T. Tanaka, "NMR study of poly ( $N$-isopropyl-acrylamide) gels near phase transition", Macromolecules, 24, 2936-2943 (1991)

8. T. Tokuhiro, S. Susman, T.O. Brun, K.J. Volin," "Li NMR relaxation in superionic $\beta$-Lithium aluminum", J. Phys. Soc. Japan, 58, 2553-2569 (1989)

9. T. Tokuhiro, "Effect of intermolecular interactions on the anisotropic rotational motions of molecules:

' $\mathrm{H},{ }^{2} \mathrm{H}$ and ${ }^{14} \mathrm{~N}$ nuclear magnetic resonance relaxation study of acetonitrile-chloroform liquid system", $J$.

Chem. Soc. Faraday Trans. 2, 84, 1793-1801 (1988)

10. T. Tokuhiro, "Nuclear quadrupole relaxation of spin 3/2", J. Mag. Reson. 76, 22-29 (1988)

11. T. Tokuhiro, L. G. Ionescu, D. S. Fung, "Effect of intermolecular interactions on the formation of micelles. Proton spin-lattice relaxation study in water-dimethylsulfoxide solutions of hexadecyltrimethylammonium bromide", J. Chem. Soc. Faraday II, 75, 975-984 (1979)

12. T. Tokuhiro, J. Freer, L. Menafra, "Proton spin-lattice relaxation study of intermolecular interactions in the methanol-dimethylsulfoxide liquid system", J. Chem. Soc. Faraday II, 75, 1388-1397 (1979)

13. B. R. Appleman, T. Tokuhiro, G. Fraenkel, C. W. Kern, "Theoretical studies of heavy-atom magnetic shielding in some small polyatomic molecules", J. Chem. Phys. 60, 2574-2583 (1974)

14. T. Tokuhiro, B. R. Appleman, G. Fraenkel, P. K. Pearson, C. W. Kern, "On a perturbed Hartreeanalysis of the magnetic susceptibility and the $\mathrm{C}-13$ and $\mathrm{O}-17$ NMR shielding constants in formaldehyde with Slater basis set", $J$. Chem. Phys 57, 20-28 (1972)

15. T. Tokuhiro, G. Fraenkel, "Spin echoes in multi-half-spin systems: Demodulatiion And high resolution", J. Chem. Phys. 55, 2797-2807

16. T. Tokuhiro, G. Frankel, "Modulation of spin echoes in multi-half-spin-system. 1 Closed formulas of Carr-Purcell spin echoes in several $\mathrm{A}_{\mathrm{a}} \mathrm{BX}_{\mathrm{X}} \quad$ systems", J. Chem. Phys. 49, 3998-4008 (1969)

21. T. Tokuhiro, L.G. Ionescu, "Temperature effect on molecular dynamics in micellar system. Proton spin-lattice relaxation study of cetyltrimethylammonium bromide in water-dimethylsulfoxide mixtures", Solution Chemistry of Surfactants, Ed. K. L. Mittal, 1, 497-506 (1979), Plenum Press

22. L. G. Ionescu, T. Tokuhiro, B. J. Czerniawski, E. S. Smith, "Formation of micelles of cetyltrimethylammonium bromide in water- dimethylsulfoxide solutions", Solution Chemistry of Surfactants, Ed. K. L. Mittal, 1, 487-496 (1979), Plenum Press

23. T. Tokuhiro, J. Freer, L. Menafra, "Proton spin-lattice relaxation study of intermolecular interactions in the methanol-dimethylsulfoxide liquid system", J. Chem. Soc. Faraday II, 75, 1388-1397 (1979)

24. L. G. Ionescu, T. Tokuhiro, B. J. Cerniawski, "Formation of micelles of Hexadecyltrimethylammonium bromide in water-N,N'- dimethylformamide solution", Bull. Chem. Soc. Japan, $52,922-924(1979)$ 


\section{SOUTH. BRAZ. J. CHEM., Vol.19, No. 19, 2011}

25. T. Tokuhiro, L. G. Ionescu, D. S. Fung, "Effect of intermolecular interactions on the formation of micelles. Proton spin-lattice relaxation study in water-dimethylsulfoxide solutions of hexadecyltrimethylammonium bromide", J. Chem. Soc. Faraday II, 75, 975-984 (1979)

26. T. Tokuhiro, L. Menafra, H. H. Szmant, "The C-13 isotope shifts in the proton magnetic resonance spectra of dimethylsulfoxide and some symmetric molecules", Rev. Latinoamer. Quim. 8, 36-39 (1977) 27. T. Tokuhiro, K. W. Woo, "Proton spin-lattice relaxation in the chloroform-toluene liquid system: A contribution to the elucidation of dynamic local structure", J. Phys. Chem. 80, 733-740 (1976)

28. T. Tokuhiro, W. G. Rothshild, "Resonance vibrational energy transfer in liquids in the repulsive potential region", J. Chem. Phys. 62, 2150-2154 (1975)

29. T. Tokuhiro, 1. Menafra, H. H. Szmant, "The contribution of relaxation and chemical Shift results to the elucidation of the structure of the water-DMSO liquid system", J. Chem. Phys. 61, 2275-2282 (1974)

30. B. R. Appleman, T. Tokuhiro, G. Fraenkel, C. W. Kern, "Theoretical studies of heavy-atom magnetic shielding in some small polyatomic molecules", J. Chem. Phys. 60, 2574-2583 (1974)

31. B. R. Appleman, T. Tokuhiro, G. Fraenkel, C. W. Kern, "Fluorine chemical shielding In $\mathrm{CH}_{3} \mathrm{~F}$ ", J. Chem. Phys. 58, 400-402 (1973)

32. T. Tokuhiro, B. R. Appleman, G. Fraenkel, P. K. Pearson, C. W. Kern, "On a perturbed Hartreeanalysis of the magnetic susceptibility and the $\mathrm{C}-13$ and $\mathrm{O}-17$ NMR shielding constants in formaldehyde with Slater basis set", J. Chem. Phys 57, 20-28 (1972)

33. T. Tokuhiro, G. Fraenkel, "Spin echoes in multi-half-spin systems: Demodulatiion And high resolution", J. Chem. Phys. 55, 2797-2807

34. T. Tokuhiro, G. Fraenkel, "The paramagnetic contribution to the $\mathrm{C}-13$ shielding constants in benzene", J. Chem. Phys. 51, 3626-3627 (1969)

35. T. Tokuhiro, G. Fraenkel, "Comment on the modulation of spin echoes in $\mathrm{A}_{\mathrm{a}} \mathrm{BX} \mathrm{X}_{\mathrm{X}}$ system", J. Chem. Phys. 51, 2769-2770 (1969)

36. T. Tokuhiro, G. Fraenkel, "Origin of linearity of Carbon-13 shift with charges: Calculation for the azines", J. Amer. Chem. Soc. 91, 5005-5013 (1969)

37. T. Tokuhiro, G. Frankel, "Modulation of spin echoes in multi-half-spin-system. 1 Closed formulas of Carr-Purcell spin echoes in several $\mathrm{A}_{\mathfrak{a}} \mathrm{BX}_{\mathrm{X}} \quad$ systems", J. Chem. Phys. 49, 3998-4008 (1969)

38. T. Tokuhiro, N. K. Wilson, G. Fraenkel, "Calculation of the Carbon-13 and proton chemical shifts in pyridine", J. Amer. Chem. Soc. 90, 3622-3628 (1968)

39. T. Tokuhiro, "Effect of molecular motion on the nuclear quadrupole resonance frequencies and linewidth in some alkyl halides", J. Chem. Phys. 47, 2353-2362 (1967)

40. T. Tokuhiro, "Vibrational and rotational effect on the nuclear quadrupole coupling constants in hydrogen, deuterium, and tritium halides", J. Chem. Phys. 47, 109- 113 (1967)

41. T. Tokuhiro, "Temperature dependence of the nuclear quadrupole relaxation time $T_{1}$ in paradichloro-benzene under constant pressure", J. Chem. Phys. 41,1147-1152 (1964)

42. T. Tokuhiro, "Effect of hindered rotation on the nuclear quadrupole resonance frequency and the linewidth in trans-1,2-dichloroethane", J. Chem. Phys. 41, 438-444 (1964)

43. T. Tokuhiro, "Nuclear quadrupole resonance spectra of halogen containing alicyclic compounds", Bull. Tokyo Institute of Technology, 57, 3-7 (1964)

44. T. Tokuhiro, "Temperature dependence of the nuclear quadrupole resonance frequencies in 1,4dihalo-genocyclohexanes", Bull. Chem. Soc. Japan. 35, 1923-1929 (1962) 